\title{
HUBUNGAN ANTARA NYERI HAID (DISMENORE) TERHADAP AKTIVITAS BELAJAR PADA SISWI KELAS XI SMA NEGERI 52 JAKARTA
}

\author{
Salsabilla Alifah Putri \\ Moch. Yunus \\ Erianto Fanani \\ Fakultas Ilmu Keolahragaan Universitas Negeri Malang \\ email: salsabilla.caca18@gmail.com
}

\begin{abstract}
Abstact: Menstrual pain (dysmenorrhea) is one of the disorders during menstruation. One of the activities that can be disrupted due to menstrual pain (dysmenorrhea) is learning activity. Preliminary study conducted by researchers shows that students who experience menstrual pain (dysmenorrhea) feel uncomfortable and not eager to follow the learning activities. The purpose of the research conducted is to find out whether there is a relationship between menstrual pain (dysmenorrhea) to learning activities undertaken by female students of class XI SMA 52 Jakarta. The method used in this research is descriptive analytic with cross sectional research design. The population is all female students of class XI SMA 52 Jakarta amount 171 people, the determination of samples by purposive sampling technique and calculate by the slovin formula obtained 120 people. The result of this research is there is a significant relationship between menstrual pain (dysmenorrhea) with learning activity $(0,000<0,05)$. The conclusion of this research is there is a significant relationship between menstrual pain (dysmenorrhea) with learning activity.
\end{abstract}

Keywords: Menstrual pain (dysmenorrhea), learning activities

\begin{abstract}
Abstrak: Nyeri haid (dismenore) merupakan salah satu gangguan saat menstruasi. Salah satu aktivitas yang dapat terganggu akibat nyeri haid (dismenore) adalah aktivitas belajar. Survei pendahuluan yang dilakukan peneliti menunjukkan bahwa siswi yang mengalami nyeri haid (dismenore) merasa tidak nyaman dan tidak bersemangat untuk mengikuti kegiatan pembelajaran. Penelitian bertujuan untuk mengetahui hubungan antara nyeri haid (dismenore) terhadap aktivitas belajar yang dilakukan oleh siswi kelas XI SMA Negeri 52 Jakarta. Penelitian ini menggunakan metode deskriptif analitik dengan desain cross sectional. Populasi penelitian ini adalah seluruh siswi kelas XI SMA Negeri 52 Jakarta berjumlah 171 siswi, penentuan sampel dengan teknik purposive sampling dan dihitung dengan rumus slovin diperoleh hasil 120 orang. Analisis data menggunakan uji korelasi rank spearman. Hasil penelitian menunjukkan bahwa terdapat hubungan yang signifikan antara nyeri haid (dismenore) dengan aktivitas belajar $(0,000<0,05)$. Kesimpulan dari penelitian ini yaitu terdapat hubungan yang signifikan antara nyeri haid (dismenore) dengan aktivitas belajar pada siswi kelas XI SMA Negeri 52 Jakarta.
\end{abstract}

Kata kunci: Nyeri haid (dismenore), aktivitas belajar

Adolesen (remaja) merupakan masa transisi dari anak-anak menjadi dewasa. Menurut World Health Organization (WHO), remaja adalah penduduk dalam rentang usia 10-19 tahun. Masa remaja merupakan masa perkembangan pada diri remaja yang sangat penting, diawali dengan matangnya organ-organ fisik (seksual) sehingga nantinya mampu bereproduksi. Pada masa remaja terdapat perubahan-perubahan yang terjadi seperti perubahan hormonal, fisik, psikologis maupun sosial, dimana kondisi tersebut dinamakan dengan masa pubertas. Salah satu tanda pubertas pada remaja putri yaitu terjadinya menstruasi (Batubara, 2012). Pada saat menstruasi, masalah yang dialami oleh hampir sebagian besar wanita adalah rasa tidak nyaman atau rasa nyeri yang hebat. Hal ini biasa disebut dengan nyeri haid (dismenore). Menurut data WHO (dalam Fahmi, 2014), di Indonesia, angka kejadian dismenore sebanyak $55 \%$ dikalangan usia produktif, dimana $15 \%$ diantaranya mengeluhkan aktivitas menjadi terbatas akibat dismenore. 
Nyeri haid (dismenore) merupakan gangguan fisik yang sangat menonjol pada wanita yang sedang mengalami menstruasi berupa gangguan nyeri/kram pada perut (Lestari, 2011). Nyeri haid (dismenore) memiliki dampak yang cukup besar bagi remaja putri karena menyebabkan terganggunya aktivitas sehari-hari. Remaja putri yang mengalami nyeri haid (dismenore) pada saat menstruasi akan merasa terbatas dalam melakukan aktivitas khususnya aktivitas belajar di sekolah. Menurut Rohmat (2013) aktivitas belajar adalah keterlibatan seseorang dalam bentuk sikap, pikiran dan perhatian dalam kegiatan belajar sebagai penunjang keberhasilan proses belajar mengajar sehingga diperoleh manfaat dari kegiatan tersebut. Remaja putri yang sedang mengalami nyeri haid (dismenore) sekaligus mengikuti kegiatan pembelajaran, dapat menyebabkan aktivitas pembelajaran menjadi terganggu, tidak bersemangat, konsentrasi menjadi menurun bahkan sulit berkonsentrasi sehingga materi yang disampaikan selama pembelajaran tidak dapat diterima dengan baik bahkan sampai ada yang tidak masuk sekolah.

Penelitian terdahulu oleh Saguni (2013) menunjukkan bahwa siswi yang mengalami gangguan dalam aktivitas belajar diakibatkan karena nyeri haid

yang dirasakan dalam proses pembelajaran. Hal ini menyebabkan siswi sulit untuk berkonsentrasi karena ketidaknyamanan yang dirasakan ketika mengalami nyeri haid. Siswi yang mengalami nyeri haid (disemenore) pada saat jam pelajaran berlangsung juga ada yang sampai meminta izin untuk pulang dan terkadang ada yang meminta izin untuk diberikan dispensasi beristirahat di ruangan UKS. Penelitian lain oleh Handayani (2011) menyebutkan bahwa dismenore merupakan salah satu penyebab utama absen sekolah pada remaja putri untuk beberapa jam atau beberapa hari. Hal tersebut dihubungkan pada pengaruh negatif terhadap aktivitas sosial pada kebanyakan remaja putri.

Remaja putri yang mengalami dismenore pada saat menstruasi mempunyai lebih banyak libur sekolah atau absen dan prestasinya kurang begitu baik di sekolah dibandingkan mereka yang tidak mengalami dismenore.

Survei pendahuluan yang dilakukan oleh peneliti didapatkan bahwa 8 dari 20 siswi pernah mengalami nyeri haid (dismenore) saat sedang mengalami menstruasi, merasakan sakit pada bagian perut dan menjalar kebawah bagian panggul, merasa kurang nyaman saat beraktivitas dan tidak bersemangat saat mengikuti pembelajaran disekolah. Berdasarkan penjelasan diatas peneliti melakukan penelitian yang bertujuan untuk mengetahui hubungan antara nyeri haid (dismenore) dengan aktivitas belajar pada siswi kelas XI SMA Negeri 52 Jakarta.

\section{Metode}

Penelitian ini menggunakan rancangan penelitian deskriptif analitik dengan desain cross sectional. Populasi yang digunakan adalah seluruh siswi kelas XI SMA Negeri 52 Jakarta sebanyak 171 orang. Sampel diambil dengan menggunakan teknik purposive sampling dan berdasarkan kriteria inklusi dan eksklusi yang dibuat peneliti, besar sampel dihitung menggunakan rumus slovin sehingga diperoleh hasil sebanyak 120 sampel.

Instrumen penelitian yang digunakan yaitu lembaran kuesioner yang berhubungan dengan nyeri haid (dismenore) dan aktivitas belajar dalam bentuk pilihan ganda (multiple choice) dan skala likert. Penelitian dilaksanakan pada bulan Mei 2017. Pengumpulan data terbagi menjadi dua tahap yaitu tahap persiapan dan tahap pelaksanaan. Tahap persiapan meliputi permohonan pengadaan penelitian dengan membuat surat izin dari fakultas yang ditujukan ke SMA Negeri 52 Jakarta, menentukan sampel berdasarkan kriteria inklusi dan eksklusi, penyusunan instrumen dan menentukan jadwal penelitian. Tahap pelaksanaan meliputi pengambilan data, pengumpulan dan pengecekan data. 
Pengambilan data dilakukan dengan cara membagikan kuesioner kepada responden yang telah memenuhi kriteria inklusi dan eksklusi dengan terlebih dahulu mengisi lembar persetujuan (informed consent). Pengolahan data yang dilakukan meliputi editing, coding, processing, dan cleaning. Analisis data yang digunakan adalah uji korelasi rank spearman dengan aplikasi SPSS versi 16 untuk melihat apakah terdapat hubungan yang signifikan antara nyeri haid (dismenore) dengan aktivitas belajar.
Hasil

Usia

Responden penelitian berjumlah 117 siswi dari 120 siswi. 3 responden tidak termasuk sebagai subyek penelitian dikarenakan kuesioner yang telah dibagikan tidak kembali. Dari 117 responden, sebanyak 61 orang berusia 17 tahun dengan persentase 53\%, dan sebanyak 56 orang berusia 16 tahun dengan persentase $47 \%$. Untuk lebih jelasnya dapat dilihat pada tabel 1 berikut.

Tabel 1. Distribusi Frekuensi Usia Responden

\begin{tabular}{ccc}
\hline Usia & Jumlah & Persentase \\
\hline 16 tahun & 56 & $47 \%$ \\
17 tahun & 61 & $53 \%$ \\
\hline Total & $\mathbf{1 1 7}$ & $\mathbf{1 0 0 \%}$ \\
\hline
\end{tabular}

\section{Usia Menarche}

Usia menarche yang dialami responden berkisar antara usia 9-15 tahun. Dari 117 siswi yang menjadi subyek penelitian, sebagian besar siswi yang mengalami menarche pada usia 12 tahun dengan jumlah 55 orang dengan presentase sebesar $47 \%$. Untuk lebih jelasnya dapat dilihat pada tabel 2 berikut.

Tabel 2. Distribusi Frekuensi Usia Menarche Responden

\begin{tabular}{lcc}
\hline \multicolumn{1}{c}{ Usia Menarche } & Jumlah & Persentase \\
\hline 9 tahun & 1 & $0.85 \%$ \\
10 tahun & 1 & $0.85 \%$ \\
11 tahun & 27 & $23 \%$ \\
12 tahun & 55 & $47 \%$ \\
13 tahun & 23 & $20 \%$ \\
14 tahun & 8 & $6.84 \%$ \\
15 tahun & 2 & $1.71 \%$ \\
\hline Total & $\mathbf{1 1 7}$ & $\mathbf{1 0 0 \%}$ \\
\hline
\end{tabular}

\section{Siklus Menstruasi}

Dari 117 siswi yang menjadi subyek penelitian, sebanyak 30 responden mengalami siklus menstruasi pendek $(<21$ hari) dengan persentase $26 \%$, sebanyak 76 responden memiliki siklus menstruasi normal (rutin setiap
21-35 hari) dengan persentase $65 \%$, sedangkan sebanyak 11 responden mengalami siklus menstruasi lama/panjang (>35 hari) dengan persentase 9\%. Untuk lebih jelasnya dapat dilihat pada tabel 3 berikut.

Tabel 3. Distribusi Frekuensi Siklus Menstruasi Responden

\begin{tabular}{ccc}
\hline Siklus Menstruasi & Jumlah & Persentase \\
\hline$<21$ hari (pendek) & 30 & $26 \%$ \\
$21-35$ hari (normal) & 76 & $65 \%$ \\
$>35$ hari (panjang) & 11 & $9 \%$ \\
\hline Total & $\mathbf{1 1 7}$ & $\mathbf{1 0 0 \%}$ \\
\hline
\end{tabular}


Kejadian Nyeri Haid (Dismenore)

Dari 117 siswi yang menjadi subyek penelitian, sebanyak 101 siswi

pernah mengalami nyeri haid (dismenore) saat menstruasi dengan persentase $86 \%$. Sedangkan sebanyak 16 siswi tidak pernah mengalami nyeri haid (dismenore) dengan persentase $14 \%$. Untuk lebih jelasnya dapat dilihat pada tabel 3 berikut.

Tabel 4. Distribusi Frekuensi Kejadian Nyeri Haid (Dismenore)

\begin{tabular}{ccc}
\hline Kelompok & Jumlah & Persentase \\
\hline Nyeri haid/dismenore & 101 & $86 \%$ \\
Tidak nyeri haid & 16 & $14 \%$ \\
\hline Total & $\mathbf{1 1 7}$ & $\mathbf{1 0 0 \%}$ \\
\hline
\end{tabular}

\section{Aktivitas Belajar}

Aktivitas belajar terbagi menjadi dua kategori yaitu terganggu dan tidak terganggu. Dari 101 siswi yang pernah mengalami nyeri haid

(dismenore) sebanyak 93 siswi menyatakan bahwa aktivitas belajar menjadi terganggu (92\%) dan sebanyak 8 siswi menyatakan bahwa aktivitas belajar tidak terganggu (8\%). Dari 16 siswi yang tidak pernah mengalami nyeri haid (dismenore) saat menstruasi, sebanyak 10 siswi menyatakan bahwa aktivitas belajar menjadi terganggu (63\%) dan sebanyak 6 siswi menyatakan bahwa aktivitas belajar tidak terganggu (37\%). Untuk lebih jelasnya dapat dilihat pada tabel 5 berikut.

Tabel 5. Kategori Aktivitas Belajar Responden

\begin{tabular}{lcccccc}
\hline \multirow{2}{*}{$\begin{array}{c}\text { Kejadian Nyeri Haid } \\
\text { (Dismenore) }\end{array}$} & \multicolumn{4}{c}{ Aktivitas Belajar } & & \multirow{2}{*}{ Total } \\
\cline { 2 - 6 } & \multicolumn{2}{c}{ Tidak terganggu } & \multicolumn{2}{c}{ Terganggu } & & \\
\cline { 2 - 7 } & $\mathbf{N}$ & $\mathbf{\%}$ & $\mathbf{N}$ & $\mathbf{\%}$ & $\mathbf{N}$ & $\mathbf{\%}$ \\
\hline Nyeri haid (dismenore) & 8 & $8 \%$ & 93 & $92 \%$ & 101 & $100 \%$ \\
\hline Tidak dismenore (menstruasi) & 6 & $37 \%$ & 10 & $63 \%$ & 16 & $100 \%$ \\
\hline Total & & & & & $\mathbf{1 1 7}$ & $\mathbf{1 0 0 \%}$ \\
\hline
\end{tabular}

Tabel 6. Hubungan antara Nyeri Haid (Dismenore) terhadap Aktivitas Belajar

\begin{tabular}{cccr}
\hline & & & Aktivitas Belajar \\
\hline \multirow{2}{*}{$\begin{array}{c}\text { Spearman's } \\
\text { rho }\end{array}$} & Nyeri haid & Correlation coefficient & $-0,436$ \\
& (Dismenore) & Sig. (2-tailed) & 0.000 \\
& $\mathrm{~N}$ & 101 \\
\hline
\end{tabular}

\section{Hasil Uji Hipotesis}

Untuk mengetahui apakah terdapat hubungan yang signifikan antara nyeri haid (dismenore) dengan aktivitas belajar, peneliti menggunakan uji korelasi rank spearman. Dari hasil analisis, diketahui koefisien korelasi sebesar $-0,436$ dan nilai Sig. $<\alpha$

$(0,000<0,05) \quad$ sehingga dapat disimpulkan bahwa terdapat hubungan yang signifikan antara nyeri haid (dismenore) terhadap aktivitas belajar pada siswi kelas XI SMA Negeri 52 Jakarta.
Tanda negatif pada koefisien korelasi menunjukkan korelasi yang terjadi antara nyeri haid (dismenore) terhadap aktivitas belajar tidak berbanding lurus, yang artinya bahwa semakin tinggi atau hebat nyeri yang dirasa, maka aktivitas belajar yang dilakukan semakin terganggu, dimana kontribusi nyeri haid (dismenore) terhadap aktivitas belajar yaitu sebesar 43,6\% menunjukkan bahwa sebanyak $56,4 \%$ terdapat faktor lain yang mempengaruhi aktivitas belajar. Untuk lebih jelasnya dapat dilihat pada tabel 6 . 


\section{Pembahasan}

Hasil penelitian selanjutnya akan dibahas lebih lanjut dengan teori yang berlaku. Karakteristik responden pada penelitian ini adalah siswi kelas XI SMA Negeri 52 Jakarta berusia 16-17 tahun yang berjumlah 117 orang. Responden terbanyak berusia 17 tahun dengan jumlah 61 siswi (53\%). Usia 1617 tahun merupakan usia masa remaja pertengahan (rentang usia 15-17 tahun) dimana pada masa tersebut remaja mengalami perubahan pada dirinya. Salah satu perubahan yang terjadi pada remaja putri adalah mengalami menstruasi yaitu proses pengeluaran darah dari vagina akibat luruhnya dinding rahim bagian dalam (Mugiati, 2016).

Dari hasil penelitian untuk usia menarche didapatkan bahwa sebagian besar responden mengalami menarche pada usia 12 tahun (47\%). Menarche merupakan menstruasi pertama yang terjadi pada masa awal remaja. Hal ini sesuai dengan teori yang menyebutkan bahwa rata-rata usia menarche pada perempuan usia 10-59 tahun di Indonesia adalah 12-13 tahun dengan kejadian awal pada usia kurang dari 9 tahun (Yusuf, 2014).

Hasil penelitian untuk siklus menstruasi menunjukkan bahwa sebagian besar responden mengalami siklus menstruasi normal (65\%). Hal ini sesuai dengan teori yang menyebutkan bahwa jarak siklus menstruasi berkisar antara 15-45 hari dengan rata-rata 28 hari (Lestari, 2011).

Hasil penelitian untuk kejadian nyeri haid (dismenore) menunjukkan bahwa dari 117 responden, hampir sebagian besar pernah mengalami nyeri haid (dismenore) saat mengalami menstruasi (86\%). Banyak faktor yang menyebabkan terjadinya nyeri haid (dismenore) pada siswi yaitu faktor psikis, fisiologi dan hormonal.

\section{Kesimpulan}

Berdasarkan hasil penelitian mengenai hubungan antara nyeri haid (dismenore) terhadap aktivitas belajar
Hasil analisa peneliti banyaknya responden yang mengalami gangguan dalam aktivitas belajar disebabkan karena nyeri haid (dismenore) yang dirasakan akan berdampak baik dari segi fisik seperti cepat letih dan tidak bersemangat maupun dari segi psikolgis seperti sulit berkonsentrasi karena rasa tidak nyaman yang timbul.

Berdasarkan hasil analisis data diketahui bahwa terdapat hubungan yang signifikan antara nyeri haid (dismenore) terhadap aktivitas belajar. Hal ini sesuai dengan penelitian yang dilakukan oleh Saguni (2013) yaitu terdapat hubungan antara nyeri haid (dismenore) dengan aktivitas belajar pada remaja putri SMA Kristen 1 Tomohon Manado yang ditunjukkan dari hasil uji statistik ChiSquare nilai $p$

$=0,000<$ alpha $=0,05$ yang berarti Ho ditolak sehungga $\mathrm{Ha}$ diterima. Hasil analisa yang didapat mengemukakan bahwa banyaknya responden yang mengalami gangguan dalam aktivitas belajar diakibatkan karena nyeri haid

yang dirasakan dalam proses pembelajaran. Hal ini menyebabkan siswi sulit untuk berkonsentrasi karena ketidaknyamanan yang dirasakan ketika mengalami nyeri haid.

Penelitian lain yang sejalan yaitu oleh Handayani (2011). Hasil uji statistik Rank Spearman didapatkan nilai $p$ sebesar 0,402 dengan signifikansi $0,003<$ taraf signifikansi $(0,05)$ sehingga dapat dinyatakan terdapat hubungan antara dismenore terhadap aktivitas belajar pada siswi SMA Muhammadiyah 5 Yogyakarta tahun 2011. Dalam penelitiannya disebutkan bahwa remaja putri yang mengalami dismenore pada saat menstruasi mempunyai lebih banyak libur sekolah atau absen dan prestasinya kurang begitu baik di sekolah dibandingkan mereka yang tidak mengalami dismenore.

pada siswi kelas XI SMA Negeri 52 Jakarta dapat ditarik kesimpulan yaitu terdapat hubungan yang signifikan antara nyeri haid (dismenore) terhadap 
aktivitas belajar pada siswi kelas XI SMA Negeri 52 Jakarta.

\section{Saran}

Berdasarkan kesimpulan diatas, maka dapat dikemukakan saran sebagai berikut:

Praktisi kesehatan masyarakat hendaknya dapat melakukan kajian dan analisis terkait masalah-masalah kesehatan teutama permasalahan kesehatan reproduksi yang terjadi

dikalangan remaja putri. Serta diharapkan mampu untuk mengembangkan media promosi kesehatan bagi remaja putri untuk memberikan pengetahuan dan informasi yang berkaitan dengan kesehatan reproduksi termasuk masalah/gangguan pada saat mengalami menstruasi, sehingga remaja putri dapat memiliki wawasan yang luas serta lebih siap

dalam menghadapi permasalahan kesehatan reproduksi.

Bagi siswi diharapkan dapat meningkatkan wawasan mengenai pengetahuan dan informasi terkait

kesehatan reproduksi khususnya gangguan saat menstruasi. Bagi siswi yang mengalami nyeri haid (dismenore) diharapkan dapat siap dan memperhatikan kondisi tubuhnya dan agar dapat menangani nyeri yang dialami dengan upaya yang benar sehingga setiap terjadi menstruasi tidak disertai dengan nyeri serta dapat menganggap nyeri haid (dismenore) sebagai fisiologi atau kejadian alami yang terjadi saat mengalami menstruasi. Bagi siswi yang tidak mengalami nyeri haid (dismenore) diharapkan dapat

selalu memperhatikan kondisi kesehatan.

Bagi sekolah hendaknya dapat menyediakan sarana serta menerapkan penatalaksaan nyeri (pain management) sebagai upaya untuk menghilangkan nyeri haid (dismenore) baik dari segi nonfarmakologi seperti pijat dan kompres air hangat maupun dari segi farmakologi seperti menyediakan obat pereda rasa nyeri serta langkah-langkah penanganan yang tepat jika mengalami nyeri haid (dismenore) sehingga dapat mengurangi siswi dengan keluhan nyeri haid (dismenore) agar tidak mengganggu aktivitas pembelajaran.

Bagi jurusan diharapkan hasil penelitian ini dapat dijadikan sebagai rujukan dalam pengembangan ilmu pengetahuan seputar kesehatan masyarakat khususnya kesehatan reproduksi.

Bagi peneliti selanjutnya diharapkan hasil penelitian ini dapat dijadikan acuan dan bahan rujukan dalam melakukan penelitian serupa dengan variabel yang lebih bervariasi dan faktor yang berbeda salah satunya faktor psikologis yang kemungkinan besar berpengaruh terhadap nyeri haid (dismenore) maupun aktivitas belajar. Selain itu peneliti

selanjutnya diharapkan dapat menggunakan sasaran yang berbeda dengan penelitian sebelumnya.

\section{Daftar Rujukan}

Batubara, Jose RL. 2010. Adolescent Development (Perkembangan Remaja). (Online). (http://saripediatri.idai.or.id/pdfi le/12-1-5.pdf), diakses 18 Februari 2017

BKKBN. 2012. Remaja Genre dan Perkawinan Dini. (Online). (http://www.bkkbn.go.id/publik asi/Documents/Policy\%20brief \%20remaja\%20\%20perkawinan \%20dini.pdf), diakses 10

Februari 2017

Diah, Pradnya Paramita. 2010. Hubungan Tingkat Pengetahuan Tentang Dismenorea dengan Perilaku Penanganan Dismenorea pada Siswi SMK YPKK I Sleman Yogyakarta. Skripsi. Surakarta: Universitas Sebelas Maret (http://opac.unisayogya.ac.id/15 80/), diakses 06 Juni 2017

Fahmi. 2014. Hubungan Antara Dismenore dengan Usia Menarche dan Indeks Massa Tubuh. (Online). (http://repository.usu.ac.id/bitstr 
eam/123456789/41010/4/Chapte

r\%20II.pdf), diakses 11 Januari 2017

Handayani. Trisna Yuni dan Dewi Rokhanawati. 2011. Hubungan Dismenorea Terhadap Aktivitas Belajar Siswi SMA Muhammadiyah 5 Yogyakarta Tahun 2011. Jurnal Kebidanan, (Online).

(http://opac.unisayogya.ac.id/15 80/), diakses 06 Juni 2017

Iswari, Kadek Dwi Pranya, dkk. 2014. Hubungan

Dismenore dengan Aktivitas Belajar

Mahasiswi PSIK FK UNUD Tahun 2014.

Jurnal Keperawatan, (Online).

(http://ojs.unud.ac.id/index.php/

coping/article/view/10780/8026) ,diakses

06 Juni 2017

Kasdu, D. 2007. Solusi Problem Wanita Dewasa. Jakarta: Puspa Swara

Kementerian Kesehatan RI. 2013. Situasi Kesehatan Reproduksi Remaja. (Online).

(http://www.depkes.go.id/downl oad.php?file=download/pusdati n/infodatin/infodatin\%20reprod uksi\%20remaja-ed.pdf), diakses 05 Februari 2017

Lestari, Ni Made Sri Dewi. 2013. Pengaruh Dismenore pada Remaja, Jurnal Ilmu Kesehatan, (Online).

(http://ejournal.undiksha.ac.id/in dex.php/semnasmipa/article/vie w/2725), diakses 15 Maret 2017 Lestari, Novita. 2011. Tips Praktis Mengetahui Masa Subur. Yogyakarta: Katahati.

Manuaba, Ida Ayu Chandranita, dkk. 2009. Memahami Kesehatan Reproduksi Wanita Edisi 2. Jakarta: EGC

Mugiati, 2016. Hubungan antara Stres dengan Perubahan Pola Menstruasi pada Mahasiswi Kebidanan Tanjungkarang, Jurnal Ilmu Kesehatan, 3 (1), (Online). (http://ejurnal.poltekke s-

tjk.ac.id/index.php/JKM/article/ view/164/156), diakses 25 Februari 2017

Ningsih, Sri Ratna dan Hikmah Sobri. 2012. Hubungan Stres Belajar dengan Gangguan Menstruasi Pada Mahasiswi Program Studi

DIII Kebidanan. Jurnal Kebidanan dan Keperawatan, (Online). 8 (1). (http://opac.unisayogya.ac.id/16 69/1/NASKAH\%20PUBLIKAS I\%20RATNA.pdf), diakses 08 Juni 2017

Notoatmodjo, Soekidjo. 2012. Metodologi Penelitian Kesehatan. Jakarta: Rineka Cipta

Novia, Ika dan Nunik Puspitasari. 2013. Faktor Resiko yang Mempengaruhi Kejadian Dismenore Primer, Jurnal Ilmu Kesehatan, (Online). (http://www.journal.unair.ac.id/f ilerPDF/Naskah\%204\%20(h96103).pdf), diakses 06 Juni 2017

Prawirohardjo, S. 2009. Ilmu kebidanan. Jakarta: Bina Pustaka Sarwono Prawirohardjo

Rohmat. 2013. Aktivitas Belajar, Hasil Belajar, Metode Diskusi Dan Pendidikan Kewarganegaraan. (Online).

(http://eprints.walisongo.ac.id/9 84/3/083911045_Bab2.pdf),diak ses 23 Maret 2017

Saguni, Fersta Cicilia Apriliani, dkk. 2013. Hubungan Dismenore dengan Aktivitas Belajar Remaja Putri di SMA Kristen I Tomohon. Jurnal Keperawatan, (Online), 1 (1), (https://ejournal.unsrat.ac.id/ind ex.php/jkp/article/view/2182), diakses 06 Juni 2017

Swarjana, I Ketut. 2012. Metodologi Penelitian Kesehatan.

Yogyakarta: CV. Andi Offset

Syaiful Bahri Djamarah. 2008. Psikologi Belajar, Edisi 2. Jakarta: Rineka Cipta

Troeman, 2015. Pengaruh Olahraga Terhadap Kejadian Dismenore. (Online). 
(http://repository.usu.ac.id/bitstr eam/123456789/43244/4/Chapte r\%20II.pdf), diakses 11 Januari 2017

Yuliani. Pungkas dan Novita Nur Hidayati. 2011. Hubungan Antara Dismenorea dengan Aktivitas Belajar Siswa SMP Negeri 4 Boyolali. Jurnal Kebidanan, (Online). (http://journal.stikeseub.ac.id/in dex.php/jkeb/article/view/91), diakses 06 Juni 2017

Yusuf, Yanti, dkk. 2014. Hubungan Pengetahuan Menarche dengan Kesiapan Remaja Putri Menghadapi Menarche di SMP Negeri 3 Tidore Kepulauan. Jurnal Keperawatan, (Online). (https://ejournal.unsrat.ac.id/ind ex.php/jkp/article/view/5272/47 85), diakses 08 Juni 2017 